\title{
Scanning Electron Microscopy Method as a Tool for the Evaluation of Selected Materials Microstructure
}

\author{
K. Pospíšil*, A. Frýbort, A. Kratochvíl, J. Macháčková \\ Infrastructure and Environmental Division, CDV - Transport Research Centre, Brno, Czech Republic \\ *Corresponding author: karel.pospisil@cdv.cz
}

\begin{abstract}
This paper introduces CDV's research on microstructure evaluation of two selected materials used in pavements or structures, i.e. cement concrete and bitumen. A Scanning Electron Microscope (SEM) has been used as the main equipment. In the case of cement concrete time-dependent changes in the microstructure of self-compacting concrete (SSC) are described. The microstructures and differences in void and pore system of matured SSC with commonly used micro-fillers are also shown here. In the case of bitumen the paper anticipates that the relationship between the composition, structure and usable properties of bitumen have not yet been clarified enough. The SEM method requires an appropriate preparation as the raw bitumen samples can not be watched directly. The oil fraction, precluding the observation, must be eliminated. Nevertheless, its removal may cause a modification of the original structure, and this might consequently have an impact on the results of the observation.
\end{abstract}

KEY WORDS: SEM, microstructure, bitumen, concrete, cement

\section{INTRODUCTION}

Two selected materials have been studied in the recent CDV's research on microstructure evaluation: cement concrete and bitumen. In the case of cement concrete a degradation process has been being observed and in the case of bitumen an appropriate way for microstructure study has been researched.

\subsection{CEMENT CONCRETE}

Recent concrete development points to an application of many types and volumes of admixtures and additions. They are added to concrete to obtain the special properties of fresh concrete (e.g. SCC - Self-compacting Concrete) or the properties of hardened concrete (HPC - Hi-performance Concrete, LWAC - Light-weight Concrete). Usage of 3 or more different types of additions (fly-ash, slag, silica-fume, fine grounded limestone or additives (plasticizers, accelerators, stabilizers, air-entered agents, etc.) is common.

This paper describes the part of work realized as a part of a project called "Long-time changes of concrete microstructure and their properties".

The structure of hydration products (subsequent re-crystallization) rising in concrete microstructure within a short time after mixing concrete is well known. A generation of neoformations in cement mortar is a never-ending process. The question is how 
the material, concrete or mortar additives and admixtures, influences the concrete and mortar properties over a long time period and mainly if there is some probability that the usage of additives and admixtures or their combination, in connection to environmental activity, can cause changes in concrete structures (e.g., re-crystallization) that deteriorate the properties of the concrete and the realized structure.

\subsection{BITUMEN}

Heavier loads, higher traffic volume and higher tire pressure demand a higher performance of pavements. A high performance pavement requires bitumen that is less susceptible to high temperature rutting or low temperature cracking (Chen et al., 2003).

Bitumen is the residue from the vacuum distillation of petroleum oil. It consists of two main fractions: asphaltenes and maltenes (Loeber et al., 2000; Loeber et al., 1998; Masson et al., 2006). The asphaltenes are defined as the bitumen fraction that is insoluble in n-heptane. Asphaltenes are polar with a higher molecular weight than maltenes. The maltenes are soluble in n-heptane, are less polar and less aromatic than the asphaltene fraction and can be further separated into resin, aromatic and saturate fractions (Bearsley et al., 2004).

Bitumen rheological and mechanical properties, controlled by the chemical and physical interactions of individual fractions, are highly dependent on the temperature (Loeber et al., 1998; Chen et al., 2003). Bitumen represents complex multicomponent mixtures whose chemical properties, or more precisely structures, have not yet been explained (Masson et al., 2006; Sebor et al., 2001). The observation of bitumen structure is not easy because of its colloidal behaviour (Loeber et al., 1998). But the research of asphaltenes structure might help to explain the bitumen rheological properties. Scanning electron microscopy and environmental scanning electron microscopy (ESEM) have both been used successfully to image the asphaltene structure (Baginska et al., 2004; Bearsley et al., 2004; Loeber et al., 1996), because they offer a three-dimensional image that can be analyzed more easily than a two-dimensional one, usually obtained from optic techniques and transmission electron microscopy (TEM) (Rahmani et al., 2003). Electron microscopy has contributed considerably to the development of theories concerning the structure, composition, and properties of components of these blends and to the interpretation of their optical microscopy and applied research results (Wilson et al., 2000).

Yet SEM is unable to observe nonconductive oil samples, because the resolution is too low. For that reason the oil phase (maltenes), which is disturbing the observation, must be removed (Loeber et al., 2000; Loeber et al., 1998;). It may cause the change of the original structure and consequently have an impact on the results of the observation. Therefore the SEM observation requires a suitable preparation method (Loeber et al., 1998; Loeber et al., 1996). There are several methods of asphaltene-paraffin removal, such as mechanical means, hot fluid, addition of surfactant agents, crystal modifiers, and precipitation by different solvents. The precipitation by different organic solvents is the one used most frequently. This method is also used to examine bitumen chemical composition (Bragado et al., 2001).

This article introduces bitumen microstructures obtained with the use of SEM that enables us to evaluate a suitable sample preparation method for the SEM observation.

A sample preparation method that will not have an impact on the internal microstructure, i.e., that it will guarantee the observed sample is a product of degradation processes and not a result of an unsuitable sample preparation method, is necessary to find in order to understand the degradation processes progressing in bitumen at a microstructure level. 


\section{CEMENT CONCRETE EXPERIMENTS}

\subsection{PARAMETERS}

For the experiment 40 different types of SCC mixtures of various types, with different amount of used admixtures or for different construction purposes, were designed. For this paper were used four mixtures marked F1, F3, F4, and F13 with a maximum amount of each type of micro-filler (stone-dust, fly-ash, limestone and slag). A complete composition of the selected concrete mixtures is presented in Table 1.

Table 1: The composition of the selected self-compacting concrete mixtures

\begin{tabular}{|l|c|c|c|c|c|}
\hline \multicolumn{2}{|l|}{ Concrete mixture prescriptions } & $\begin{array}{c}\mathrm{F} 1 \\
\text { (stone-dust) }\end{array}$ & $\begin{array}{c}\mathrm{F} 3 \\
\text { (fly-ash) }\end{array}$ & $\begin{array}{c}\text { F4 } \\
\text { (limestone) }\end{array}$ & $\begin{array}{c}\text { F13 } \\
\text { (slag) }\end{array}$ \\
\hline Cement 42.5 R & $\mathrm{kg}$ & 400 & 400 & 400 & 400 \\
\hline Fine aggregates 0-4 $\mathrm{m}$ & $\mathrm{kg}$ & 830 & 870 & 700 & 760 \\
\hline Coarse aggregates 4-8 mm & $\mathrm{kg}$ & 165 & 230 & 230 & 230 \\
\hline Coarse aggregates $8-16 \mathrm{~mm}$ & $\mathrm{~kg}$ & 582 & 550 & 550 & 550 \\
\hline Filler & $\mathrm{kg}$ & 160 & 160 & 280 & 220 \\
\hline Superplasticizer & $\mathrm{kg}$ & 4 & 4 & 4 & 4 \\
\hline Water & $\mathrm{kg}$ & 190 & 185 & 175 & Unknown \\
\hline
\end{tabular}

Specimens (150mm testing cubes) of the mixture were prepared in February 2003. Specimens were demoulded after 24 hours and deposited into water at room temperature. Specimens of concrete for microscope study were prepared in April 2007. The presented pictures of concrete microstructure are about 4 years old. For SEM specimen preparation we used a diamond-charged saw and cut off a small piece from the edge of each cube.

All concrete specimens with a fracture area approximately $5 \times 5 \mathrm{~mm}$ and micro-fillers were attached by self-adhesive carbon tape to a specimen holder and then coated by a golden film. Through coating a better image resolution was obtained due to removing the surface electric charge.

\subsection{CEMENT CONCRETE MICROSTRUCTURE}

The observation made by SEM method showed that there are some voids in the concrete microstructure with crystals of ettringite $\mathrm{Ca}_{6} \mathrm{Al}_{2}(\mathrm{OH})_{12} \cdot 24 \mathrm{H}_{2} \mathrm{O}$ and portlandite $\mathrm{Ca}(\mathrm{OH})_{2}$. Crystals of ettringite can form the shapes of needles, fibres or fan-shaped agglomerations and crystals of portlandite form shapes of tables or chips within a free space of voids (see Figures 1 and 2).

If these products of hydration reaction fill all the space of pores, it can produce stress leading to cracks or damage of the concrete. In this case the voids are relatively unfilled, as crystals of ettringite are still harmless for concrete strength.

A low amount of portlandite in the concrete matrix provides better sulphate attack resistance. On the other hand portlandite keeps a high alkalic $\mathrm{pH}$ in concrete, which is the principle of steel reinforcement passivation.

Only spherical fly-ash particles can be clearly viewable in the concrete matrix (see Figure 3). Other used fillers with variform particles are indefinable in hardened concrete. 


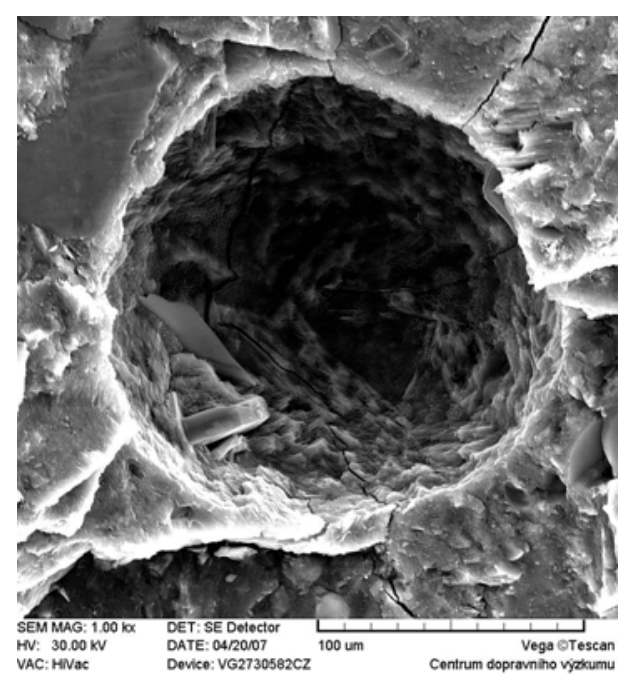

F1 - stone-dust

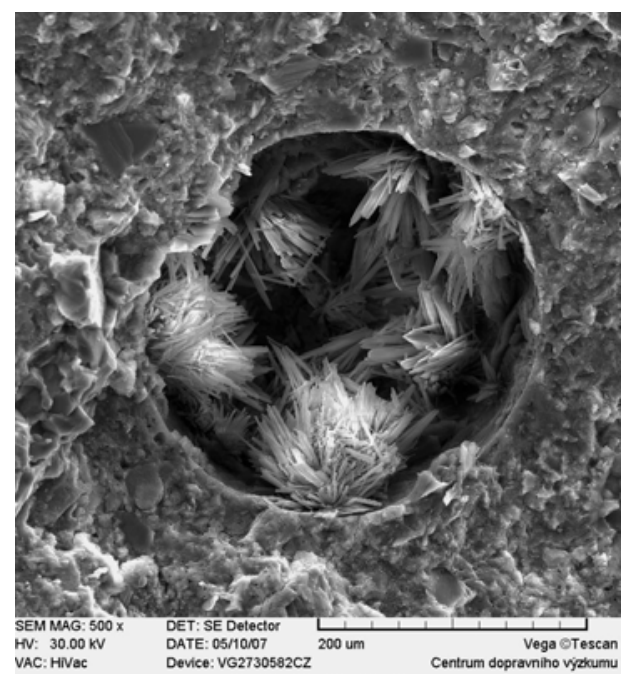

F4 - limestone

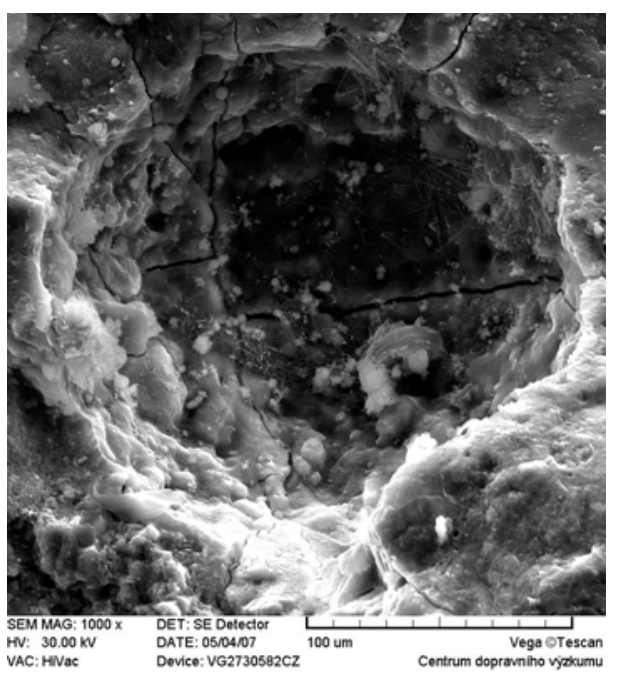

F3 - fly-ash

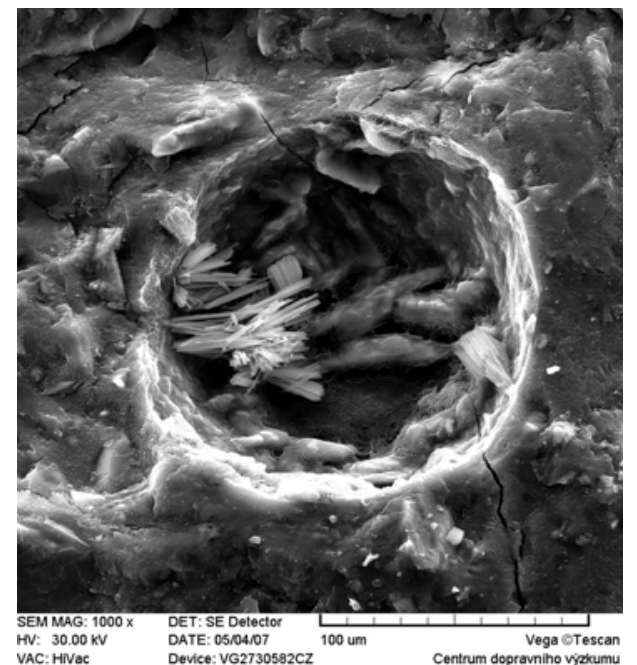

F13 (slag)

Figure 1: Voids in concrete matrix - various amount of ettringite and portlandite crystals
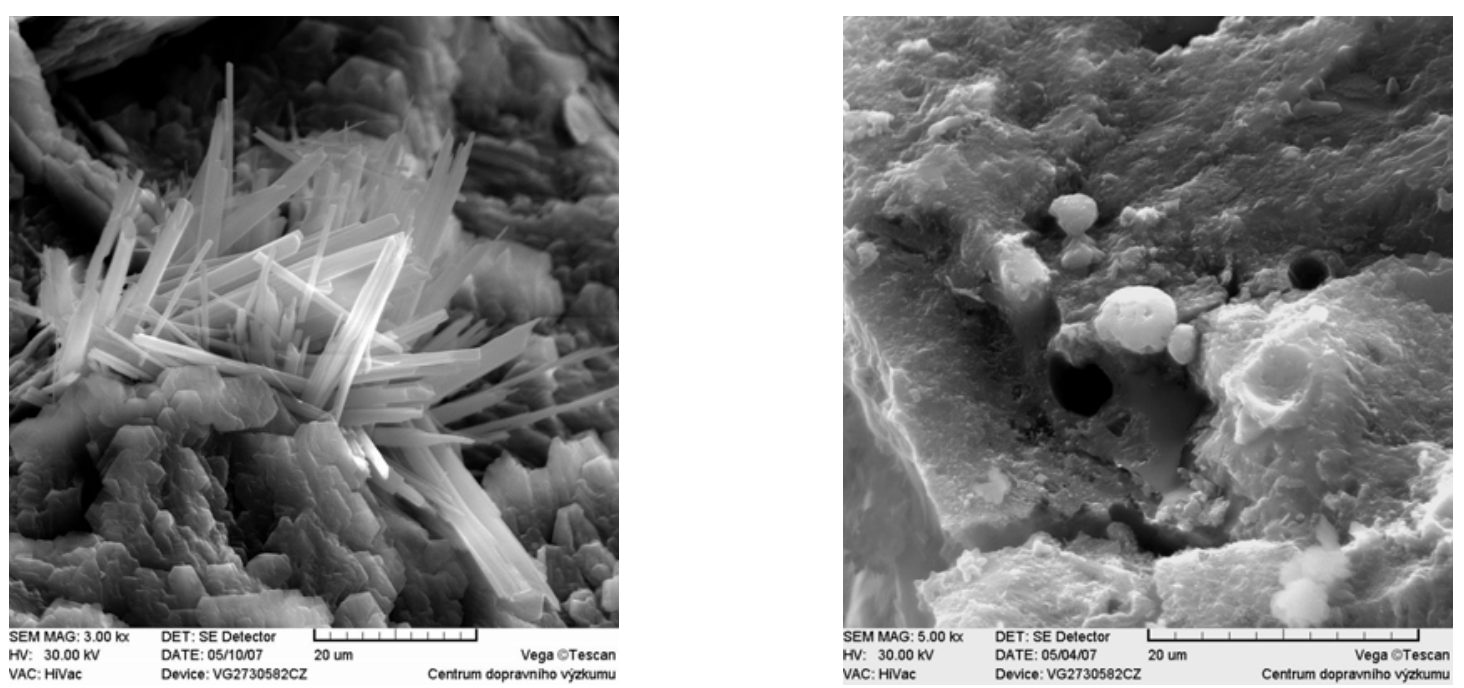

Figure 2: Detailed view of ettringite needles Figure 3: Fly-ash particles clearly viewable and portlandite tables in void space in the concrete matrix 


\section{BITUMEN EXPERIMENTS}

\subsection{PARAMETERS}

The bitumen binders 70/100 from two producers were used for the observation. Their basic properties are shown in Table 2. Asphaltenes were obtained from the precipitation with n-heptane.

Table 2: Bitumen parameters

\begin{tabular}{|c|c|c|c|}
\hline & \multicolumn{3}{|c|}{ Sample } \\
\hline & 1 & 2 & 3 \\
\hline Bitumen type & Air-blown 70/100 & $\begin{array}{c}\text { Straight-run } \\
\text { vacuum residue }\end{array}$ & $70 / 100$ \\
\hline Penetration value at $25^{\circ} \mathrm{C}$ & 85 & 109 & 89 \\
\hline Softening point $\left[{ }^{\circ} \mathrm{C}\right]$ & 45.2 & 41.2 & 43.9 \\
\hline The yields of asphaltene recovery & & & \\
\hline CSN 656073 & 14.0 & 6.6 & - \\
\hline Procedure A & 11.7 & 3.3 & - \\
\hline Procedure B & 13.8 & 5.7 & - \\
\hline Procedure $\mathrm{C}$ & 16.4 & 6.0 & - \\
\hline Procedure D, E & - & - & 7.4 \\
\hline
\end{tabular}

\subsection{THE PROCEDURES OF THE SAMPLE PREPARATION}

There are several techniques of oil phase (maltenes) elimination described in ČSN 656073 (Czech National Standard) and some additional ones mentioned in Baginska et al., 2004; Bearsley et al., 2004; Bragado et al., 2001; Rahmani et al., 2003:

- The procedure based on ČSN 65 6073: dissolution of $1 \mathrm{~g}$ of sample in $40 \mathrm{ml}$ of n-heptane, kept in the dark over night, 1 hour of boiling under the reflux condenser, 2 hours of keeping in dark, filtration through the filter paper, 1 hour of washing the filter paper in a Soxhlet extraction apparatus with n-heptane, 1 hour of washing the filter paper in a Soxhlet extraction apparatus with toluene, pouring the solution into a glass bowl, toluene evaporation above the water bath, 1 hour of drying in $110^{\circ} \mathrm{C}$, measuring, repeating to the constant weight.

- Procedure A: dissolution of $1 \mathrm{~g}$ of sample in $40 \mathrm{ml}$ of $\mathrm{n}$-heptane, 1 hour of boiling under the reflux condenser, 2 hours of keeping in the dark, filtration through the filter paper, 1 hour of washing the filter paper in a Soxhlet extraction apparatus, drying.

- Procedure B: dissolution of $1 \mathrm{~g}$ of sample in $40 \mathrm{ml}$ of n-heptane, kept in the dark over night, filtration through the glass filter paper Whatman GF/A, washing with n-heptane, 3 hours of washing the filter paper in a Soxhlet extraction apparatus, 8 hours of washing the filter paper in a Soxhlet extraction apparatus, drying.

- Procedure C: dissolution of $1 \mathrm{~g}$ of sample in $40 \mathrm{ml}$ of $\mathrm{n}$-heptane, 10 minutes of boiling, filtration through the glass filter paper Whatman GF/A, 1 hour of washing with n-heptane, drying.

- Procedure D: dissolution of 0,8-1 g of sample in $40 \mathrm{ml}$ of n-heptane, kept in the dark for 24 hours, filtration through the glass filter paper Whatman, washing with n-heptane, drying. 
- Procedure E: dissolution of 0,8-1 g of sample in $40 \mathrm{ml}$ of n-heptane, kept in the dark for 24 hours, filtration through the glass filter paper Whatman, washing with n-heptane, 2 hours of washing the filter paper in a Soxhlet extraction apparatus with n-heptane, drying.

All the bitumen samples precipitated in n-heptane were coated and subsequently observed using the scanning electron microscope.

\subsection{RESULTS AND DISCUSSION}

The basic properties of applied asphalts from the two producers are introduced in Table 2. The different values of n-heptane asphaltene yields in samples 1 and 2-3 can be explained with the partial conversion of resins into asphaltenes. It can be supposed that this conversion occur during the bitumen processing, the air-blowing. Thus the values of yields of asphaltenes recovery in the air-blown sample 1 are higher than in samples 2 and 3.

The results of the observation are visible at Figures 1-5. The structure of the sample prepared according to the ČSN 656073 method is shown in Figure 4. It can be seen that the structure is smooth, featureless and shapeless. No microstructure is visible. It can be concluded that the procedure disrupted the original structure. This destruction could arise as the consequence of the procedure, when the dilution was poured into a glass bowl and the solvent evaporated.

For comparison the microstructure of the sample prepared according to the procedure A is introduced in Figure 5, in the same magnification (5000x). The microstructure of this sample consisted of asphaltenes micelles and is evident here.

In accordance with the authors' opinion, the size of asphaltenes micelles and the extent of their aggregation were influenced by the chemical type of the primary product and by the technology of asphalt processing in their samples. The observation of asphaltenes using SEM enabled us to discern micelles to a size $110-260 \mathrm{~nm}$. The research of the Ural asphalts identified smaller particles in comparison with the Venezuelan asphalts. But the extent of aggregation was bigger.

In Figures 6-8 the microstructure of asphaltenes samples prepared according to varied preparation methods (procedure A, B, C) are represented in the same magnification $(10000 \mathrm{x})$.

The methods differed from each other in the time of the sample preparation and various procedures of maltenes removal from the samples. Procedure $\mathrm{C}$ was the shortest and no extraction in a Soxhlet extraction apparatus was used. On the contrary, procedure B was the longest and extraction in a Soxhlet extraction apparatus lasting 11 hours was used. The purpose of this divergence was to evaluate the suitability of sample preparation procedures for SEM observation. The microstructure similar in all samples is apparent regardless of the chosen preparation procedure. It can be concluded that the procedures $\mathrm{A}, \mathrm{B}$, and $\mathrm{C}$ are equal considering the impact on the change of the original structure. From a time and technical point of view procedure $\mathrm{C}$ is the least demanding.

Figure 9 represents a sample marked as 2 in Table 2 prepared according to ČSN method. 


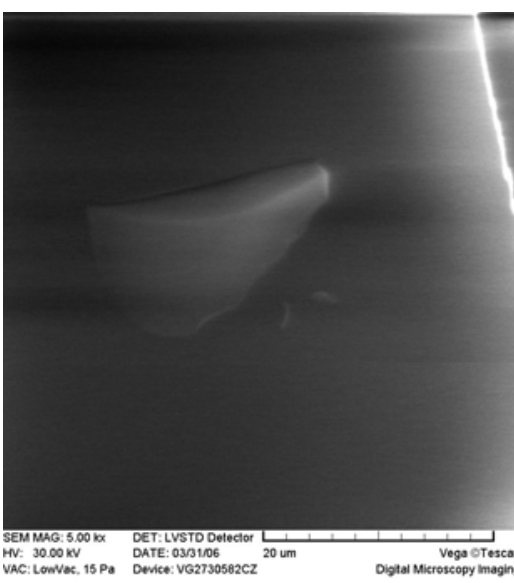

Figure 4: ČSN method

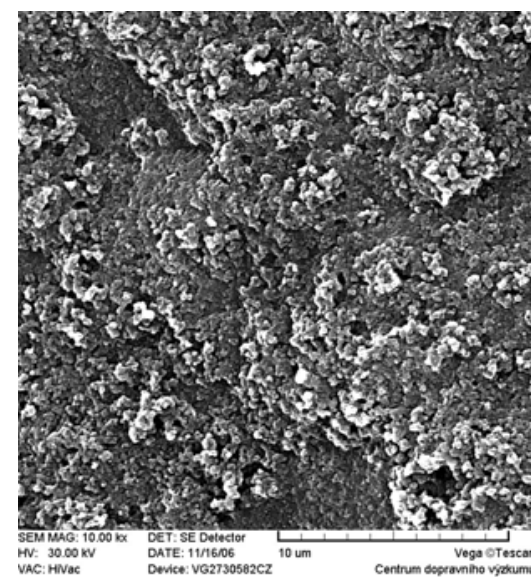

Figure 7: Procedure B

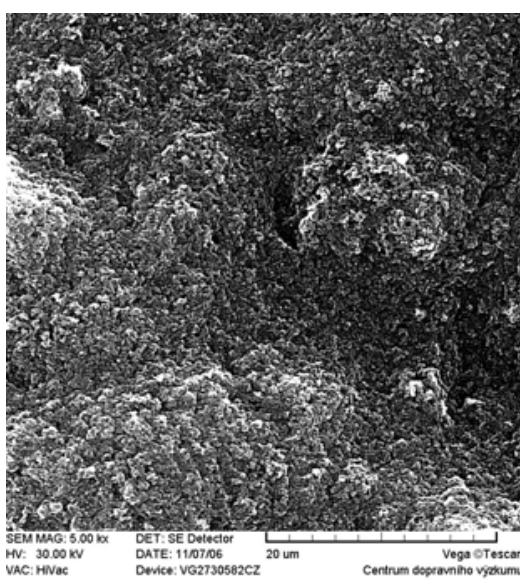

Figure 5: Procedure A

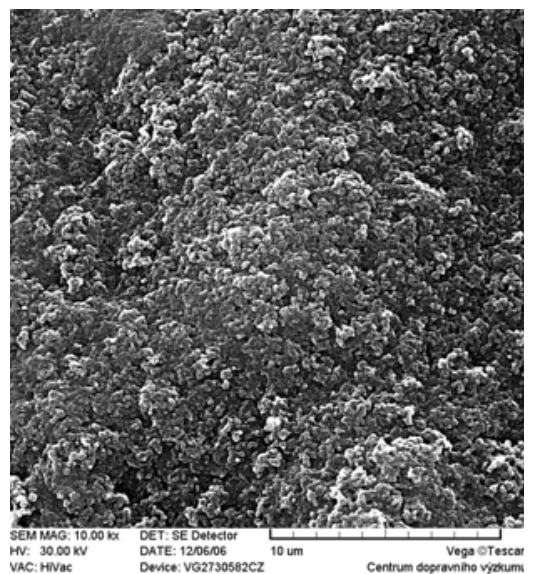

Figure 8: Procedure C

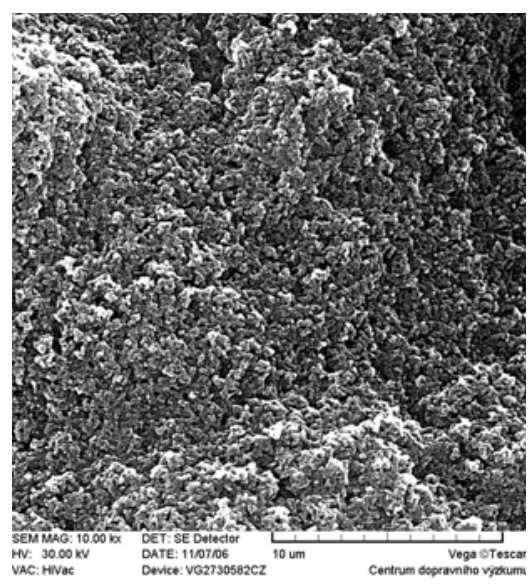

Figure 6: Procedure A

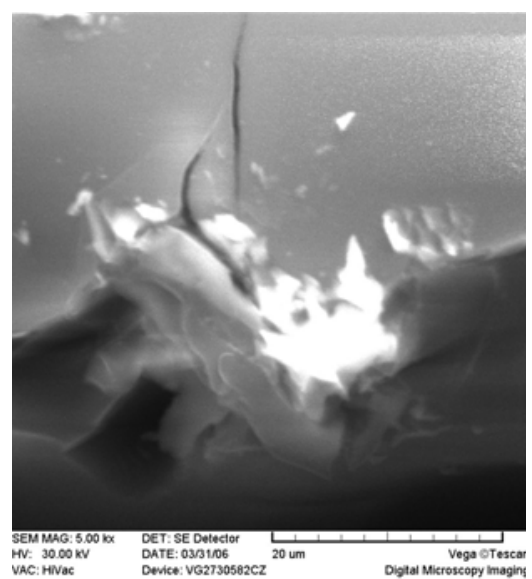

Figure 9: ČSN method

\section{CONCLUSION}

It can be supposed that the cement concrete microstructure investigation will lead to an understanding and obtaining knowledge of the relationship between concrete or mortar microstructure and their properties. As the concrete will be still maturing the investigation of all specimens will be repeated periodically during the solving of the project. For a comparison between laboratory prepared samples and samples affected by field conditions several additional samples of different types of matured concrete will be taken from existing structures with known concrete mixture composition.

The represented tentative results of bitumen microstructure research show that the study of bitumen microstructure is very deeply affected by the method of sample preparation. It is obvious that the preparation technique influences the microstructure itself. The procedure based on ČSN 656073 completely damaged the original asphaltene structure and so this technique can not be applied for the SEM observation. The tests will continue with all three types of samples using each of the described methods.

The object of following research will focus on whether the structural modification is caused in the preparation method or the sample type. The search for a considerate preparation and observational method is a prerequisite of the objective appraisal of degradation processes 
evidently progressing in asphalts, but not yet demonstrably documented at a microstructure level.

\section{ACKNOWLEDGMENTS}

The research described in this paper was established within the scope of research project of the Ministry of Transport of the Czech Republic under contract No. MD 04499457501.

The authors would like to thank The Research Institute of Inorganic Chemistry (Litvinov), namely Mr. Černý and Paramo, a.s. (Pardubice), and Mr. Plitz and Mr. Švadlák for their immense efforts in preparing the samples for observation.

\section{REFERENCES}

Baginska K., Gawel I., 2004. Effect of origin and technology on the chemical composition and colloidal stability of bitumens, Fuel Processing Technology, Vol. 85, p. 1453-1462.

Bearsley S., Forbes A., Haverkamp R. G., 2004. Direct observation of the asphaltene structure in paving-grade bitumen using confocal laser-scanning microscopy, J. Microsc., Vol. 215, 2004, p. 149-155.

Bragado G. A. C., Guzman E. T. R., Yacaman M. J., 2001. Preliminary studies of asphaltene aggregates by low vacuum scanning electron microscopy, Petroleum Science and Technology, Vol. 19, No. 12, 2001, p. 45-53.

Chen J.-S., Liao M.-C., Lin C.-H., 2003. Determination of polymer content in modified bitumen, Materials and Structures, Vol. 36, p. 594-598.

ČSN 656073 (Czech National Standard), Petroleum products. Determination of asphaltene by $n$-heptane, 1973 (in Czech language).

Loeber L., Alexandre S., Muller G., Triquigneaux J.-C., Jolivet Y., Malot M., 2000. Bituminous emulsions and their characterization by atomic force microscopy, J. Micros., Vol. 198, 2000, p. 10-16.

Loeber L., Muller G., Morel J., Sutton O., 1998. Bitumen in colloid science: a chemical, structural and rheological approach, Fuel, Vol. 77, No. 13, p. 1443-1450.

Loeber L., Sutton O., Morel J., Valleton J.-M., Muller G., 1996. New direct observations of asphalts and asphalt binders by scanning electron microscopy and atomic force microscopy, J. Microsc., Vol. 182, 1996, p. 32-39.

Masson J.-F., Leblond V., Margeson J., 2006. Bitumen morphologies by phase-detection atomic force microscopy, J. Microsc., Vol. 221, p. 17-29.

Rahmani S., McCaffrey W., Elliott J. A. W., Gray M. R., 2003. Liquid-phase behavior during the cracking of asphaltenes, Ind. Eng. Chem. Res., Vol. 42, p. 4101-4108.

Sebor G., Blazek J., 2001. Technology of road asphalts production and their quality, Proc. Conference on Asphalt Pavements 2001, Ceske Budejovice (Czech Republic), p. 133-139 (in Czech language).

Wilson A., Fuchs G., Scramoncin C., Martin D., Planche J. P., 2000. Localization of the polymer phase in bitumen/polymer blends by field emission cryo-scanning electron microscopy, Energy Fuels, Vol. 14, p. 575-584. 